\title{
Inland thinning of the Amundsen Sea sector, West Antarctica
}

\author{
Andrew Shepherd, Duncan J. Wingham, and Justin A. D. Mansley \\ Centre for Polar Observation and Modelling, University College London, London, UK
}

Received 4 October 2001; revised 13 February 2002; accepted 17 February 2002; published 16 May 2002.

[1] Together with the Pine Island glacier (PIG), the Thwaites (TG) and Smith (SG) glaciers are the principal drainage systems of the Amundsen Sea (AS) sector of Western Antarctica. Here we use satellite radar altimetry and interferometry to show that a rapid thinning of ice has occurred within the fastest flowing sections of all AS outlet glaciers. The pattern of thinning extends to distances greater than $150 \mathrm{~km}$ inland. Between 1991 and 2001, the TG and SG thinned by more than 25 and $45 \mathrm{~m}$ at their grounding lines, and a total of $154 \pm 16 \mathrm{~km}^{3}$ of ice (or $0.43 \mathrm{~mm}$ of eustatic sea level rise) was lost from the AS sector glaciers to the ocean. We show that the thickness changes may have caused the PIG, TG, and SG to retreat inland by over 8,4 , and $7 \mathrm{~km}$ respectively, in line with independent estimates of grounding line migration. INDEX TERMS: 1827 Hydrology: Glaciology (1863); 1863 Hydrology: Snow and ice (1872); 6924 Radio Science: Interferometry; 9310 Information Related to Geographic Region: Antartica

\section{Introduction}

[2] The West Antarctic Ice Sheet (WAIS) contains enough water to raise global sea levels by several metres were it to be discharged rapidly into the oceans [Warwick et al., 1996]. The WAIS bedrock is well below sea level and in places deepens inland [Lythe et al., 2000], and this particular configuration has fuelled speculation as to how stable the ice sheet would be if it were to advance or retreat [Barcilon and MacAyeal, 1993; Weertman, 1974]. Of the three major WAIS drainage systems (Figure 1), the Amundsen Sea (AS) sector has been considered the most vulnerable to changes at its margins [Hughes, 1981; Mercer, 1978; Oppenheimer, 1998] because the grounded ice sheet discharges directly into the ocean with no significant ice shelf barrier. Around $700,000 \mathrm{~km}^{3}$, or $\sim 1.1 \mathrm{~m}$ eustatic sea level rise of ice is frozen within the AS sector of the WAIS [Rignot, 2001a], and $\sim 160 \mathrm{~km}^{3}$ of ice is drained into the ocean each year through the Pine Island (PIG), Thwaites (TG), and Smith (SG) glacier systems $\left(75 \mathrm{~km}^{3} \mathrm{yr}^{-1}\right.$ for the PIG in Rignot [1998], $77 \mathrm{~km}^{3} \mathrm{yr}^{-1}$ for the TG in Rignot [2001b] and $\sim 10 \mathrm{~km}^{3} \mathrm{yr}^{-1}$ for the SG based upon net accumulation in [Vaughan et al., 1999]). These glaciers account for the vast majority $(>90 \%)$ of the ice discharge from the AS sector [Mcintyre, 1985].

[3] The first direct observations of Antarctic mass imbalance showed that elevation changes within the AS sector were amongst the most pronounced in all of Antarctica [Wingham et al., 1998]. On average, a $\sim 430,000 \mathrm{~km}^{2}$ region of the AS sector, including the PIG and TG drainage basins, thinned by $11.7 \pm 1.0 \mathrm{~cm} \mathrm{yr}^{-1}$ (equivalent to $1.26 \pm 0.11$ of the mean snow accumulation rate) between 1992 and 1996 [Wingham et al., 1998]. Studies at the ice-sheet margins showed that the PIG grounding line retreated over $5 \mathrm{~km}$ inland [Rignot, 1998] during the same period. More detailed elevation measurements revealed that that retreat was due to extensive thinning of the grounded glacier, resulting in a loss of over $40 \mathrm{~km}^{3}$ of ice [Shepherd et al., 2001]. The majority of this loss occurred within the $\left(\sim 5000 \mathrm{~km}^{2}\right)$ central trunk of the PIG and was associated with the rapid flow of ice [Shepherd et al., 2001], although the initial cause of the retreat remains uncertain.

[4] This study extends those previous high-resolution measurements of elevation change and ice flow velocity of the PIG to include the neighbouring TG and SG in order to determine the spatial extent of ice thinning within the AS sector as a whole. Between 1992 and 1996, the TG grounding line also retreated inland, but at a slower rate of $\sim 0.4 \mathrm{~km} \mathrm{yr}^{-1}$ [Rignot, 2001b]. However, the magnitude of retreat was also dependent upon the glacier geometry, and if the TG were thinning at a rate comparable to that of the PIG (up to $1.6 \mathrm{~m} \mathrm{yr}^{-1}$ close to its grounding line in [Shepherd et al., 2001]) this would be a sizable mass loss to the ocean. Moreover, it is possible that the retreats of the PIG and the TG are related events, and this could reflect a more widespread thinning of grounded ice throughout the entire AS sector of the WAIS.

\section{Data and Methodology}

[5] We used European Remote Sensing (ERS-1 and ERS-2) satellite radar altimeter measurements to determine elevation changes in the AS sector of the WAIS between 1991 and 2001. We computed differences between altimeter range measurements at crossing-points of the satellite ground track to determine changes in surface elevation through time [Wingham et al., 1998]. We found no correlation between changes in elevation and changes in backscattered power, and so we applied no empirical correction for potential fluctuations in radar scattering properties. Using data recorded during 35-day orbit repeat cycles, we formed time-series of elevation change at each orbit crossing-point within the entire AS sector [Shepherd et al., 2001]. In this way, we were able to detect changes in elevation at the finest possible resolution afforded by the ERS altimeters. The diameter of the altimeter footprint was $\sim 10 \mathrm{~km}$ at the ice surface and the mean separation of crossing-point locations was $13 \mathrm{~km}$.

[6] We calculated the average 9-year rate of elevation change from each time-series, and interpolated these data onto a regular grid using a quintic triangulation scheme (Figure 2). The root mean square deviation of the average elevation rate was $0.02 \mathrm{~m} \mathrm{yr}^{-1}$. In order to exclude measurements contaminated by ocean tides, we discarded data that were recorded seaward of the grounded ice sheet prior to interpolation. To accurately delimit floating and grounded ice, we used the limits of tidal flexure of the PIG [Rignot, 1998] and TG [Rignot, 2001b]. For the SG, which is less well documented, we mapped the hinge line using differential satellite radar interferometry (SRI) following the method of Rignot [1996]. Elsewhere, we used a combination of digital coastline data [British Antarctic Survey et al., 1993] and imagery from the Advanced Very High Resolution Radiometer [Ferrigno et al., 2001]. Some elevation data were also rejected in regions of complex topography or incoherent radar backscatter, such as the Bear Peninsula and the western margin of the TG terminus.

[7] Previously, a coherent pattern of ice thinning was spatially correlated with regions of fast ice flow in the lower reaches of the PIG [Shepherd et al., 2001]. The ice flow velocity of the PIG was mapped using SRI, and we produced a similar map covering the 


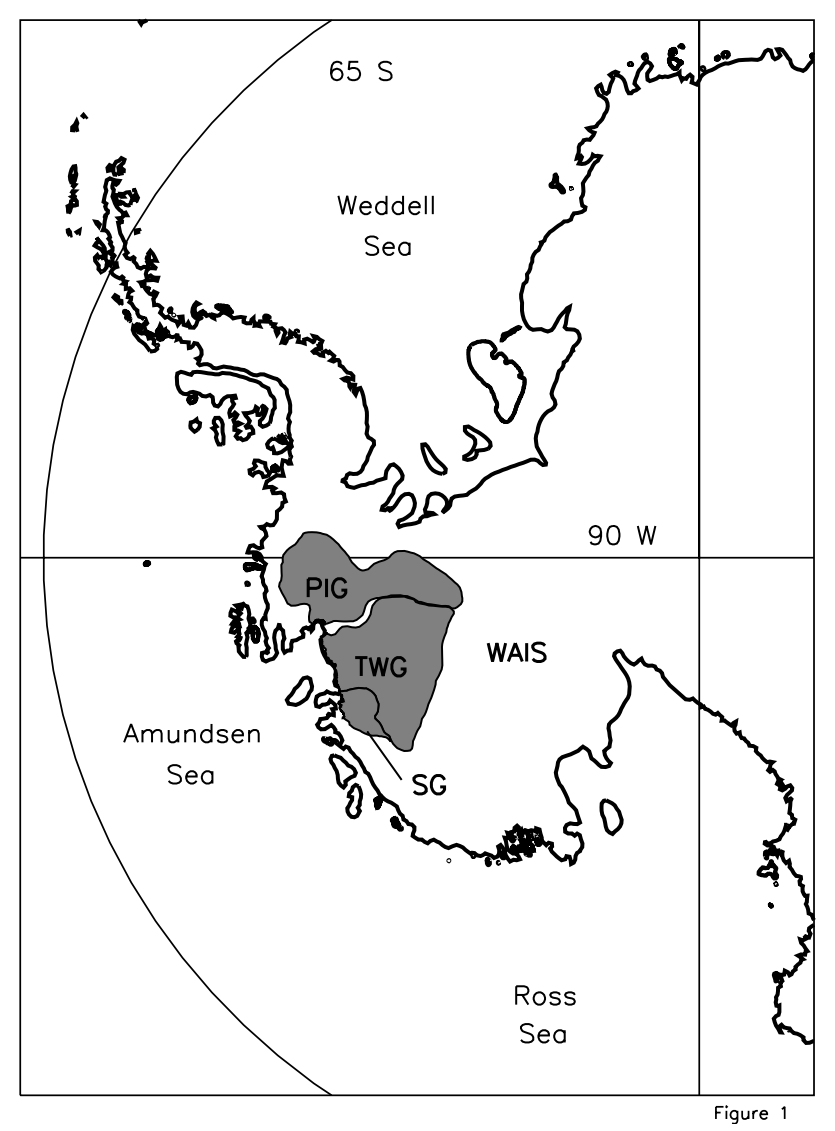

Figure 1. Map showing the location of the Pine Island (PIG), Thwaites (TG) and Smith (SG) glacier drainage basins that form the Amundsen Sea (AS) sector of the West Antarctic ice-sheet (WAIS). Basins were delimited from ice mass-balance velocities (see text). For SG, we include the drainage sector of the western tributary, Kohler Glacier.

downstream sections of the TG and the SG (contoured in Figure 2). We combined $\sim 200$ ERS SAR scenes from ascending and descending orbits to form interferometric mosaics of ice speed [Goldstein et al., 1993; Shepherd et al., 2001]. The topographic signal was removed using a combination of interferometer- and altimeter-derived elevation data. The standard deviation of velocity differences in overlapping regions within these mosaics was $\sim 50$ $\mathrm{m} \mathrm{yr}^{-1}$. There were no direct velocity measurements for grounded ice with which to control our interferometric solutions. Instead, we used the code of Budd and Warner [1996] to produce a map of ice sheet balance velocity - the flow speed required to maintain the current WAIS form - from which we selected regions of near-zero ice motion. The SRI velocity mosaic includes the westernmost tributary of the SG (Kohler glacier, which according to E. Rignot (personal communication) may actually be an altogether separate ice flow), the fastest flowing $\sim 150 \mathrm{~km}$ section of the TG, and the remainder of the AS coastline eastwards to the PIG. Data limitations restricted the areal extent of the velocity mosaic to $\sim 17 \%$ $\left(33,000 \mathrm{~km}^{2}\right)$ of the TG and $\sim 15 \%\left(\sim 4000 \mathrm{~km}^{2}\right)$ of the SG drainage basins (see Figure 2, inset).

[8] In order to illustrate the pattern of ice flow further inland, where SAR data were not available, we contoured the map of balance velocity at low flow speeds (Figure 2). The balance velocity may be inaccurate as a result of uncertainties in the net accumulation [Vaughan et al., 1999] and ice thickness [Lythe et al., 2000], or where the ice sheet is not in a state of mass balance. Whilst the approximate locations of the PIG, TG and SG are clearly delimited in the balance velocity map, a more detailed inspection reveals that the TG has a pattern of ice flow that is spatially dissimilar to the balance velocity prediction [Bamber and Rignot, 2002]. However, in the absence of additional SRI velocity measurements, we use the balance velocity to best illustrate the interior ice-sheet flow distribution.

\section{Results and Discussion}

[9] The mean rate of elevation change of the AS sector of the WAIS between 1991 and 2000 was $-0.09 \pm 0.02 \mathrm{~m} \mathrm{yr}^{-1}$. A more pronounced pattern of thinning occurred coincident with the fast flowing sections of the TG and SG drainage systems (Figure 2), in line with changes observed previously in the PIG [Shepherd et al., 2001]. The maximum rate of thinning was $2.6 \pm 0.5 \mathrm{~m} \mathrm{yr}^{-1}$ and $4.8 \pm 0.3 \mathrm{~m} \mathrm{yr}^{-1}$ at the grounding lines of the TG and SG respectively. Whilst the degree of thinning diminished inland, the pattern of falling elevation was apparent at distances greater than $150 \mathrm{~km}$ from the glacier termini (e.g. Figure $3 \mathrm{~b}$ ). The average rate of elevation change within the AS sector as a whole was comparable to the expected 9-year snowfall variability $\left(7 \mathrm{~cm} \mathrm{yr}^{-1}\right.$ based upon the 5-year estimate in [Wingham et al., 1998]) and the expected 9-year variability in surface ablation $\left(11 \mathrm{~cm} \mathrm{yr}^{-1}\right.$ based

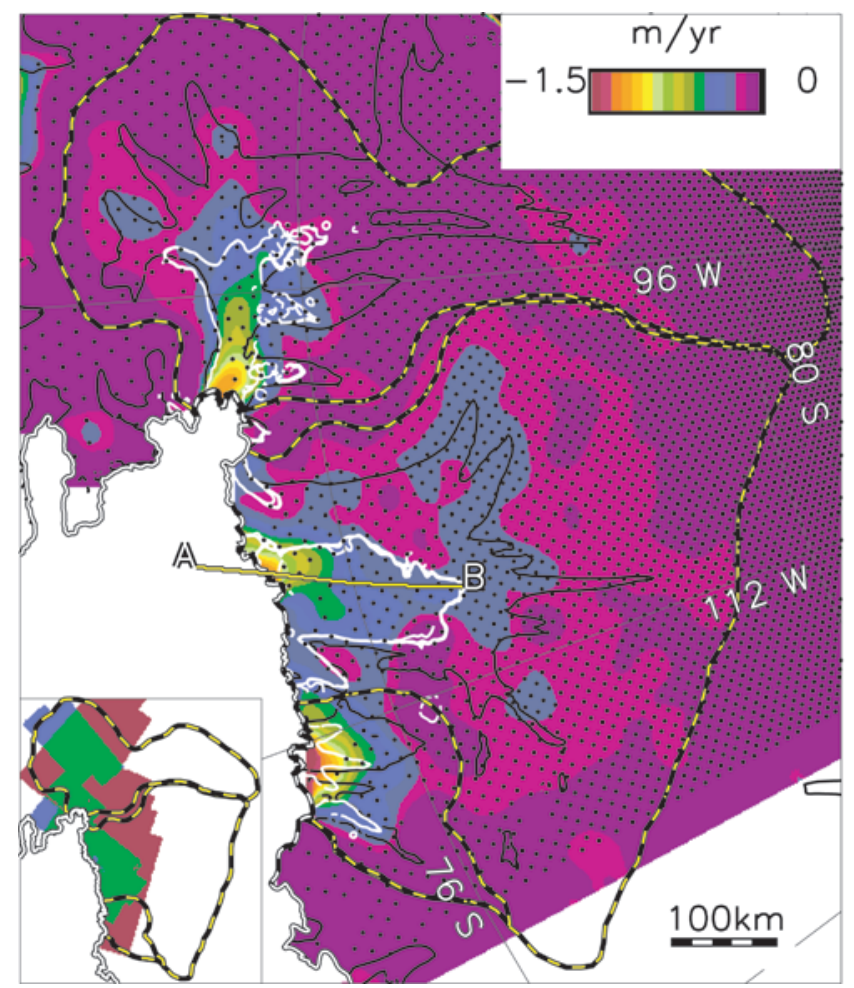

Figure 2. Rate of elevation change of the Pine Island, Thwaites and Smith glacier drainage basins determined from ERS radar altimeter measurements recorded between 1991 and 2001. Altimeter data-points used in the interpolation are shown as black dots, and drainage basins are delimited with dotted yellow margins. Superimposed are contours of ice surface velocity, determined from ERS synthetic aperture radar (SAR) interferometry $(200 \mathrm{~m}$ $\mathrm{yr}^{-1}$ in white) and considerations of ice-sheet mass balance $(50 \mathrm{~m}$ $\mathrm{yr}^{-1}$ in black). Inset is a map of the SAR data coverage showing ascending (red) and descending (blue) ERS orbits and regions of overlap between the two (green). The SG proper forms a crown shaped structure, and the Kohler glacier tributary lies to the west of this system. 

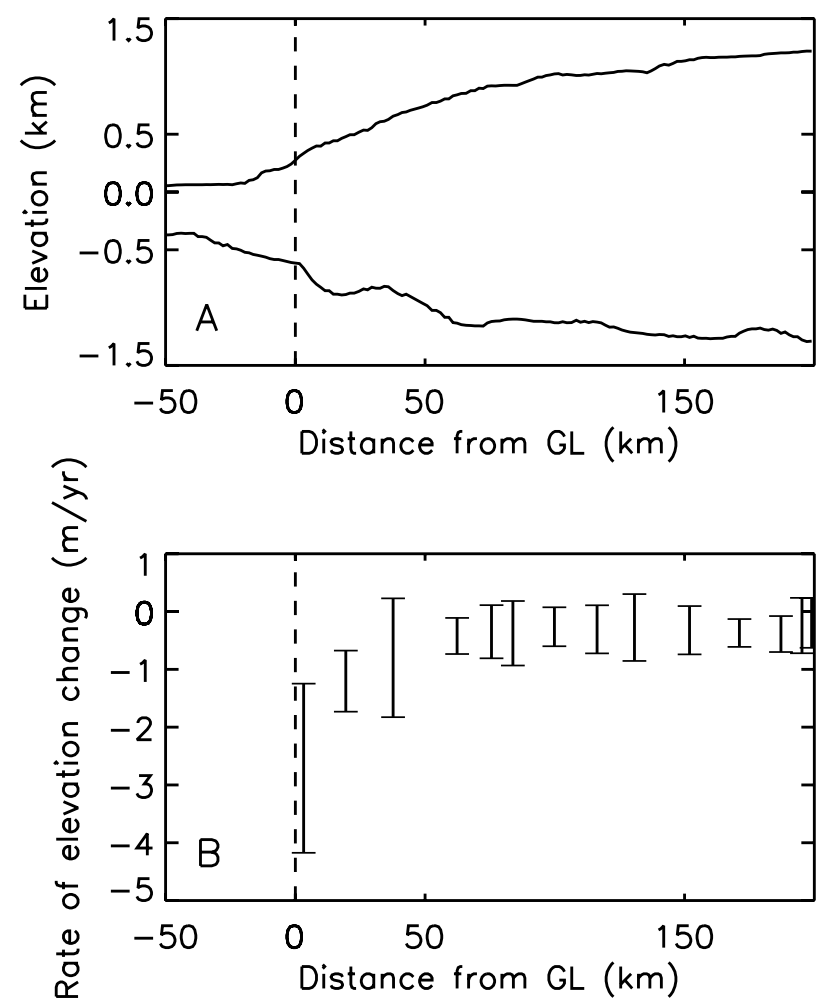

Figure 3. Ice sheet elevation (a) and rate of elevation change (b) determined along a stream-wise transect of the Thwaites Glacier (line $\mathrm{AB}$ in Figure 2) passing the grounding line (GL).

upon the 7-year estimate in [Shepherd et al., 2001]). Some of this change may simply reflect natural fluctuations in the surface mass balance - direct meteorological data are too remote $(\sim 2000 \mathrm{~km}$ distant) to rule out such a possibility. This is not to say that the wider AS sector thinning (Figure 2) is the result of fluctuations in the surface mass balance; merely that it could be.

[10] Coastal ice thinning causes marine terminating glaciers to retreat inland. As ice at the grounding line (the junction between ice, bedrock and ocean) thins it becomes buoyant, resulting in inland migration of the point of floatation. The rate of retreat is related to the bedrock and surface slope and the buoyancy of the glacier ice [Stuiver et al., 1981]. Ignoring periodic movements due to ocean tides $(\sim 1 \mathrm{~km}$ in Rignot [1998]), we used coarse $(5 \mathrm{~km})$ resolution bedrock [Lythe et al., 2000] and surface [Bamber and Bindschadler, 1997] elevation data to estimate the inland migration of the AS sector glacier grounding lines as a result of the ice thinning. The maximum rates of retreat along the PIG, TG and SG margins were $0.8,0.31$ and $0.73 \mathrm{~km} \mathrm{yr}^{-1}$, in line with independent estimates derived from SRI $\left(1.2 \pm 0.3 \mathrm{~km} \mathrm{yr}^{-1}\right.$ for the PIG in Rignot [1998] and $0.4 \pm 0.1 \mathrm{~km} \mathrm{yr}^{-1}$ for the TG in Rignot [2001b]). The underestimate of the PIG retreat rate may be explained by the relatively large $(13 \mathrm{~km})$ separation between the elevation change measurement and the grounding line.

[11] The thinning of the PIG was largely confined to the central glacier trunk - the fastest flowing section of the glacier - which rests within a narrow subglacial trough some $\sim 500 \mathrm{~m}$ deeper than the surrounding bedrock [Shepherd et al., 2001]. Less detailed ice thickness data for the TG and the SG [Lythe et al., 2000] suggest that no such distinct trough is present beneath either glacier, and it is difficult to identify the boundary of the thinning regions using a simple topographical constraint. At the ice surface, the trunk of the PIG was roughly coincident with the $\sim 200 \mathrm{~m} \mathrm{yr}^{-1}$ velocity contour [Shepherd et al., 2001]. We used this same boundary to delimit the fast and slow flowing sections of the TG and the SG from our SRI map of ice velocity (Figure 2). For SG, we do not include the western tributary (Kohler glacier) as no altimeter data fell within this region. The regions of fast-flow constitute areas of 7400 and $2300 \mathrm{~km}^{2}$ on the TG and the SG, and the 9-year average rate of elevation change of these sections was $-0.55 \pm 0.09$ and $-3.21 \pm 0.24 \mathrm{~m} \mathrm{yr}^{-1}$. However, the TG has thinned at a significant rate (relative to expected fluctuations in accumulation) over a much larger inland area, beyond the boundary of the $200 \mathrm{~m} \mathrm{yr}^{-1}$ ice velocity contour (Figure 2). We used the $50 \mathrm{~m} \mathrm{yr}^{-1}$ mass-balance and $200 \mathrm{~m} \mathrm{yr}^{-1}$ SRI velocity contours to delimit ice flowing at intermediate speeds for the TG. This $50,000 \mathrm{~km}^{2}$ region, which includes sections of the cold based ice-sheet, thinned at an average rate of $0.21 \pm 0.03 \mathrm{~m} \mathrm{yr}^{-1}$.

[12] The reduction in thickness of the fastest flowing ice within the AS sector of the WAIS was far greater (at least 5 (TG) and up to 29 (SG) times the expected variability in surface mass balance) than any reasonable reduction in snow accumulation or increase in ablation. It is likely that the thinning reflects changes in ice volume, and that the timescale for the process is that of an ice dynamic fluctuation. Assuming a density of $917 \mathrm{~km} \mathrm{~m}^{-3}$, we estimate that the TG and the SG have lost, on average, $3.7 \pm 0.6$ and $6.7 \pm 0.5 \mathrm{Gt}$ of ice each year since 1991. This mass loss must result from glacier dynamics, and appears to be correlated with regions of fast ice motion (Figure 2). However, the TG and SG are dissimilar ice flows. TG drains a volume of ice around $\sim 10$ times greater than the $\mathrm{SG}$ and has a broad $(\sim 80 \mathrm{~km})$ terminus that extends as a $\sim 100 \mathrm{~km}$ ice tongue into the AS. In contrast, the SG is a relatively narrow $(\sim 10 \mathrm{~km})$ outlet glacier that drains a small region of the AS sector bounded between subglacial mountains. Ice speed peaks at $3.5 \mathrm{~km} \mathrm{yr}^{-1}$ on the floating tongue of the TG, whereas the SG reaches a modest maximum rate of around $800 \mathrm{~m}$ $\mathrm{yr}^{-1}$ as it flows past the Dotson Ice Shelf.

[13] Whilst processes that may result in ice dynamic fluctuations can occur over a wide range of time periods [Alley and Whillans, 1984; Fowler and Shiavi, 1998; Payne, 1995], it is likely that the mechanism that has caused the PIG to thin may be taking place at some intermediate $\left(10^{2}\right.$ to $\left.10^{3} \mathrm{yr}\right)$ timescale [Shepherd et al., 2001]. If this timescale is also representative of the TG and SG elevation trends, and the rate of mass loss does not diminish, the evolution of the thinning may have a significant impact upon the ice-dynamics of the AS sector. Direct measurements of bedrock elevation in the AS are sparse, and existing data do not permit detailed modeling of either the TG or SG geometry. However, unpublished airborne radar-echo data recorded in 1979 [Lythe et al., 2000] including a $\sim 100 \mathrm{~km}$ trajectory close to the centre of the TG (Figure 3a) indicate that the bedrock slope is more gradual than the dip of the sharp subglacial trough that lies beneath the PIG [Shepherd et al., 2001]. Although interpolated bedrock elevations for the SG are unreliable due to the proximity of subglacial mountains, it is certain that the glacier flow regime is quite distinct from that of the PIG or TG. The substantial differences between the geometry and dynamics of the PIG, TG and SG may result in a separate evolutionary response to the ice thinning for each glacier.

[14] The mean ice thickness of the fast-flowing section of the TG was $1586 \mathrm{~m}$, and this area has thinned at an average rate of $0.03 \% \mathrm{yr}^{-1}$. Around $63 \%$ of the TG rests below sea level, and the current rate of mass loss can be sustained for $\sim 1500$ years before the glacier will become afloat. By this stage, the ice dynamics of the TG would be substantially altered, and this may impact upon the flow of the surrounding ice within the WAIS interior. Although in terms of ice discharge the SG is an order of magnitude smaller than the TG, the elevation changes there will have a more immediate impact if they continue unabated. Assuming a mean ice thickness of $623 \mathrm{~m}$ [Bamber and Bindschadler, 1997; Lythe et al., 2000], the SG has thinned by more than $4.6 \%$ in the past 9 years, and the mass loss is equivalent to 
$106 \%$ of the annual accumulation. The SG appears to be considerably out of mass balance, and the present rate of thinning can only be sustained for 153 years.

\section{Conclusions}

[15] Since 1991, the TG and SG have thinned by as much as 2.6 and $4.8 \mathrm{~m} \mathrm{yr}^{-1}$. The reduction in ice thickness was at least 5 times greater than expected variability in snowfall or ablation, and must have resulted from glacier dynamics. The pattern of ice thinning was largely confined to the fastest flowing sections of the TG and SG (Figure 2), and the average rate of elevation change of ice flowing at speeds greater than $200 \mathrm{~m} \mathrm{yr}^{-1}$ was $-0.55 \pm 0.09 \mathrm{~m}$ $\mathrm{yr}^{-1}$ and $-3.21 \pm 0.24 \mathrm{~m} \mathrm{yr}^{-1}$. Ice traveling at intermediate speeds $\left(50-200 \mathrm{~m} \mathrm{yr}^{-1}\right)$ along the TG thinned at an average rate of $0.21 \pm$ $0.03 \mathrm{~m} \mathrm{yr}^{-1}$. A more diffuse surface lowering of $0.09 \pm 0.03 \mathrm{~m}$ $\mathrm{yr}^{-1}$ occurred across the remainder of the ice-sheet interior. Whilst this signal was comparable to expected fluctuations in the surface mass balance, it is equally possible that this thinning too is the result of ice dynamics.

[16] The rapid thinning of the downstream sections of the TG and SG is in line with previous measurements of elevation change at the neighbouring PIG [Shepherd et al., 2001]. In total, the glaciers of the WAIS AS sector have lost over $150 \mathrm{~km}^{3}$ of ice to the ocean during the past 9 years. Assuming this reduction reflects changes in ice $\left(\rho_{\mathrm{ICE}}=917 \mathrm{~kg} \mathrm{~m}^{-3}\right)$ as opposed to snow, the mass loss is equivalent to $0.43 \mathrm{~mm}$ of eustatic sea level rise. Whilst this increase is small in comparison to other anticipated changes in global sea level [Warwick et al., 1996], the glaciers of the AS sector are major conduits for ice drainage from the WAIS, and the evolutionary impact of coastal ice thinning upon the cold interior remains uncertain.

[17] During the past 9 years the principal glaciers of the AS sector have thinned and retreated in unison. This behaviour is in contrast to that observed within other drainage systems elsewhere in the WAIS. In the past, unsteady flow within ice streams at the Siple coast has resulted in significant interactions between neighbouring drainage systems [Anandakrishnan and Alley, 1997]. Here, the ice-stream dynamics appear sufficiently separate as to render such "water piracy" an unlikely event. It seems more likely that the glacier retreats have resulted from a common cause affecting the entire AS sector seaward of the grounded ice sheet. However, the evolutionary response of the Pine Island, Thwaites and Smith glaciers to the ice thinning may, in the long term, be determined by their own characteristic geometry.

[18] Acknowledgments. This work was supported by the UK Natural Environment Research Council. We thank the European Space Agency for provision of ERS radar data.

\section{References}

Alley, R. B., and I. M. Whillans, Response of the East Antarctica Ice-Sheet to sea-level rise, J. Geophys. Res., 89, 6487, 1984.

Anandakrishnan, S., and R. B. Alley, Stagnation of Ice Stream C, West Antarctica by water piracy, Geophysical Research Letters, 24, 265-268, 1997.
Bamber, J. L., and R. A. Bindschadler, An improved elevation dataset for climate and ice-sheet modelling: Validation with satellite imagery, Annals of Glaciology, 25, 1997.

Bamber, J. L., and E. Rignot, Non-steady flow observed in West Antarctica from INSAR and balance velocities, Annals of Glaciology, 34, 2002.

Barcilon, V., and D. R. MacAyeal, Steady flow of a viscous ice stream across a no-slip free-slip transition at the bed, J. Glaciol., 39, 167-185, 1993.

British Antarctic Survey, Scott Polar Research Institute, and World Conservation Monitoring Centre, Antarctic Digital Database, 1993.

Budd, W. F., and R. C. Warner, A computer scheme for rapid calculations of balance-flux distributions, Annals of Glaciology, 23, 21-27, 1996.

Ferrigno, J. G., J. L. Mullins, J. Stapleton, P. S. Chavez Jr, M. G. Velasco, R. S. Williams Jr., G. F. Delinski Jr., and D'A. Lear, AVHRR Antarctic Mosaic, I-2560, 2001.

Fowler, A. C., and E. Shiavi, A theory of ice-sheet surges, J. Glaciol., 44, $104-118,1998$

Goldstein, R. M., H. Engelhardt, B. Kamb, and R. M. Frolich, Satellite radar interferometry for monitoring ice-sheet motion - Application to an Antarctic ice stream, Science, 262, 1525-1530, 1993.

Hughes, T. J., The weak underbelly of the West Antarctic Ice Sheet, J. Glaciol., 27, 518-525, 1981.

Lythe, M. B., D. G. Vaughan, and the BEDMAP Consortium, BAS Miscellaneous, 9, 2000.

Mcintyre, N. F., The dynamics of ice sheet outlets, Journal of Glaciology, 31, 99-107, 1985.

Mercer, J. H., West Antarctic Ice sheet and CO2 greenhouse effect: A threat of disaster, Nature, 271, 321-325, 1978.

Oppenheimer, M., Global warming and the stability of the West Antarctic Ice Sheet, Nature, 393, 325-332, 1998.

Payne, A. J., Limit-cycles in the basal thermal regime of ice sheets, J. Geophys. Res., 100, 4249-4263, 1995.

Rignot, E., Tidal motion, ice velocity and melt rate of Petermann Gletscher, Greenland, measured from radar interferometry, J. Glaciol., 42, 476485, 1996.

Rignot, E., Fast recession of a West Antarctic glacier, Science, 281, 549551, 1998.

Rignot, E., Analysis of ice flow changes in the Antarctic using ERS interferometry, Annals of Glaciology, in press, 2001a.

Rignot, E., Evidence for rapid retreat and mass loss of Thwaites Glacier, West Antarctica, J. Glaciol., 47, 2001 b.

Shepherd, A., D. J. Wingham, J. A. D. Mansley, and H. F. J. Corr, Inland thinning of Pine Island Glacier, West Antarctica, Science, 291, 862-864, 2001.

Stuiver, M., G. H. Denton, T. J. Hughes, and J. L. Fastook, History of the marine ice sheet in West Antarctica during the last glaciation: A working hypothesis, in The Last Great Ice Sheets, edited by G. H. Denton and T. J. Hughes, pp. 319-346, Wiley Interscience, New York, 1981.

Vaughan, D. G., J. L. Bamber, M. Giovinetto, J. Russell, and A. P. R. Cooper, Reassessment of net surface mass balance in Antarctica, J. Climate, 12, 933-946, 1999.

Warwick, R., C. Le Provost, M. Meier, J. Oerlemans, and P. Woodworth, Climate Change 1995: The science of climate change, pp. 359-405, 1996.

Weertman, J., Stability of the junction of an ice sheet and an ice shelf, J. Glaciol., 13, 1974

Wingham, D. J., A. Ridout, R. Scharroo, R. Arthern, and C. K. Shum, Antarctic elevation change from 1992 to 1996, Science, 282, 456-458, 1998.

A. Shepherd, D. J. Wingham, and J. A. D. Mansley, Centre for Polar Observation and Modelling, University College London, Gower Street, London WC1E 6BT, UK. 